\section{Pediatria \\ Altura final após tratamento com CETOCONAZOL EM MENINOS PORTADORES DE PUBERDADE PRECOCE FAMILIAL}

A puberdade precoce familial restrita ao sexo masculino (PPFM) é uma causa rara de puberdade precoce (PP) devido à secreção precoce de testosterona pelas células de Leydig, independente das gonadotrofinas (Gns), resultado de mutações do receptor de LH. Esta puberdade tem início, geralmente, entre I e 4 anos de idade, com rápida virilização e baixa estatura. São propostas duas abordagens terapêuticas: cetoconazol, ou um antiandrógeno e um inibidor da aromatase. Como pode ocorrer ativação das Gns, acrescenta-se um agonista. O cetoconazol é um inibidor do citocromo P450 que inibe a síntese de andrógenos testiculares e das supra-renais. $\bigcirc$ antiandrógeno antagoniza a ação androgênica em nível de receptor e o inibidor da aromatase bloqueia a conversão de andrógenos a estrógenos. Alguns autores relataram resultados destas terapias: cinco meninos tratados com cetoconazol por um período médio de 6,2 anos, alcançando $173 \mathrm{~cm}$ de altura. Esta terapia estendeu-se por um período de 5 a 10 anos e não se observou hepatotoxicidade. Apenas um menino apresentou discreto e transitório aumento de transaminases. Observou-se que estas crianças, após 10 anos de idade, apresentavam um aumento do $\mathrm{LH}$. Os autores concluem que o cetoconazol é eficaz e bem tolerado, bloqueando a puberdade e melhorando a previsão de altura final. Se houver intolerância, resta a segunda opção terapêutica.

\section{Comentário}

O PPFM, também conhecido como testotoxicose, é uma situação própria dos homens da família. O histórico do paciente pode revelar a presença de homens com baixa estatura e que também tiveram PP. O tratamento adequado pode reverter este quadro.

Nuvarte Setian

\section{Referência}

Soriano-Guillén L, Lahlou N, Chauvet G, Roger M, Chaussain JL. Adult height after ketoconazole treatment in patients with familial male-limited precocious puberty. J Endocrinol Metab 2005;90: |47-5I.

\section{Emergência e Medicina Intensiva}

\section{A COMBINAÇÃO DO BALANÇO CARGA/FORÇA E DA FREQÜÊNCIA RESPIRATÓRIA/VOLUME CORRENTE COMO PREDITORES DA EVOLUÇÃO DO DESMAME}

○ desmame da ventilação pulmonar mecânica (VPM) invasiva e não invasiva permanece como um desafio para a equipe multidisciplinar em intensivismo adulto e, principalmente, em pediatrial,2. Vassilakopoulos T. et al, em 20063, publicaram um estudo prospectivo avaliando 124 pacientes consecutivos de uma unidade de terapia intensiva para adultos, multidisciplinar e universitária, com o objetivo principal de verificar se a combinação de um índice de carga muscular ventilatória (FRNC) e um de força muscular (PI/PiMáx) poderia dar informação prognóstica da evolução do desmame.

Foi avaliado o índice de resistência (balanço carga/força), calculado como a média da pressão inspiratória máxima (PI), durante a VPM controlada sobre a pressão inspiratória máxima (PiMáx). Os pacientes foram acompanhados por 48 horas e este índice foi comparado com o índice de respiração rápida superficial $($ IRS $=$ FRNC) e outros índices, para 75 pacientes pré-extubação. Os valores limiares dos índices foram validados prospectivamente em outro grupo de 45 pacientes consecutivos.

A análise discriminativa demonstrou que a relação PI/PiMáx e o IRS foram os únicos índices que permaneceram no modelo (função do modelo $D=7.6228 \times P I / P i M a ́ x=0.0158 \times I R S-$ 2.374). No ponto de corte de $D=0,5$, obteve-se $94 \%$ de sensibilidade, $67 \%$ de especificidade e $87 \%$ de classificações corretas. Simplificando-se o modelo discriminativo ( $D=15 \mathrm{xPI} /$ PiMáx +0.03xIRS-5), no ponto de corte de $D=1$, os resultados foram semelhantes (sensibilidade $89 \%$, especificidade $67 \%$ e 85\% de classificações corretas).

Os autores concluíram que a combinação dos índices PI/ PiMáx e IRS, em uma função discriminativa simplificada, é útil em predizer a evolução do desmame de adultos em até 48 horas após a extubação.

\section{Comentário}

A grande contribuição deste estudo 3 é a demonstração de que a combinação do IRS com a PI/PiMáx apresenta boa acurácia para predizer a evolução do desmame de adultos em até 48 horas após a extubação, fornecendo informação prognóstica não oferecida por qualquer índice isolado. O IRS é considerado como uma resposta do controle respiratório para um aumento da carga da respiração ${ }^{4}$, e a combinação do IRS e da PI/PiMáx avalia a resposta à carga e à força muscular, ou seja, avalia a resistência da musculatura ventilatória.

O índice PI/PiMáx foi o único que permaneceu no modelo para pacientes que necessitaram de VPM prolongada (tempo $V P M \geq 7$ dias), que provavelmente são aqueles com endurance mais limitada; enquanto o IRS foi o único índice que permaneceu para pacientes com curto tempo de VPM (tempo VPM $<7$ dias).

Cíntia Johnston

Werther B. de Carvalho

\section{Referências}

I. Chang AT, Boots RJ, Brown MG, Paratz J, Hodges PW. Reduced inspiratory muscle endurance following successful weaning from prolonged mechanical ventilation. Chest 2005; I 28(2):553-9.

2. Noizet O, Leclerc F, SadikA, Grandbastien B, Riou Y, Dorkenoo A, et al. Does taking endurance into account improve the prediction of weaning outcome in mechanically ventilated children? Crit Care 2005;9(6):798-807.

3. Vassilakopoulos T, Routsi C, Sotiropoulou C, Bitsakou C, Stanopoulos I, Roussos $\mathrm{C}$, et al. The combination of the load/force balance and the frequency/idal volume can predict weaning outcome. Intensive Care Med 2006;32 (5):684-9I

4. McIntyre NR, Cook DJ, Ely EW Jr, Epstein SK, Fink JB, Heffner JE, et al. Evidence-based guedlines for weaning and discontinuing ventilatory support: a collective task force facillitated by American College of Chest Physicians, the American Association for Respiratory Care, and the American College of Critical Care Medice. Chest 200 I; 120 (6 Suppl):375-95. 